\title{
Evaluation and Treatment of Erectile Dysfunction in the Aging Male: A Mini-Review
}

\author{
Maarten Albersen ${ }^{a, b}$ Hazem Orabi ${ }^{a, c}$ Tom F. Lue ${ }^{a}$ \\ a Department of Urology, University of California at San Francisco, San Francisco, Calif., USA; b Department of \\ Urology, University Hospitals Leuven, Leuven, Belgium; ' ${ }^{\circ}$ Department of Urology, Assiut University, Assiut, Egypt
}

\section{Key Words}

Aging male $\cdot$ Erectile dysfunction $\cdot$ Pathophysiology Penis - Phosphodiesterase-5 inhibitors

\begin{abstract}
Before the 20th century, individuals often did not live beyond the reproductive years, and sexuality of the elderly was not an issue. However, in the current era it is known that as life expectancy improves, both men and women are seeking to preserve their sexuality into old age. While the appreciation of sexuality persists with aging, a decline in sexual activity is typically seen with, and can be attributed to both general health problems as well as specific sexual dysfunctions. Erectile dysfunction is the most frequently diagnosed sexual dysfunction in the older male population. This mini-review provides an overview of contemporary literature concerning epidemiology, pathophysiology, assessment and treatment of erectile dysfunction in the aging male.
\end{abstract}

Copyright $\odot 2011$ S. Karger AG, Basel

\section{Introduction}

Before the 20th century, individuals often did not live beyond the reproductive years, and sexuality of the elderly was not an issue. More recently, it was generally assumed that a loss of sexuality was natural and inevitable with aging, which resulted in little attention being given to sexual behavior and treatment of sexual dysfunctions in the older population. However, in the current era it is known that as life expectancy improves, both men and women are seeking to preserve their sexuality into old age. While the appreciation of sexuality persists with aging, a decline in sexual activity is typically seen with, and can be attributed to both general health problems as well as specific sexual dysfunctions. In a large US study, the proportion of males who were sexually active declined from $83.7 \%$ in the age group $57-64$ years to $38.5 \%$ in the age group $75-85$ years [1]. In a smaller pilot study in a cohort of 50 patients with a mean age of 81 years, Smith et al. [2] reported that the main reason for being sexually inactive in older men was erectile dysfunction (ED), the condition defined as the persistent inability to attain and maintain penile erection sufficient for sexual intercourse [3]. It is likely the most thoroughly studied sexual dysfunction in men and the most common sexual complaint of men presenting to their healthcare providers [4]. The advent of safe oral therapy for the treatment of ED has brought attention to the disease and likely results in increased treatment-seeking behavior, also in the aging male. Despite the overwhelming success of these oral phosphodiesterase- 5 inhibitors (PDE5I), the demand for pharmacotherapeutic and surgical options for ED continues to rise as a result of the increased proportion of elderly in the population as well as the increasing recognition that approximately one

\section{KARGER}

Fax +4161306 1234 E-Mail karger@karger.ch www.karger.com
(C) 2011 S. Karger AG, Basel

0304-324X/12/0581-0003\$38.00/0

Accessible online at:

www.karger.com/ger
Maarten Albersen, MD

Laboratory of Experimental Urology, Department of Urology

University Hospitals Leuven, Herestraat 49

BE-3000 Leuven (Belgium)

Tel. +32 163469 30, E-Mail Maarten.albersen@uzleuven.be 
third of ED patients do not respond to PDE5I [5]. This is especially applicable to the older patient with multiple pathophysiological alterations in erectile mechanisms. Therefore, ED remains a topic of interest to physicians treating the aging and older male. This review will address erectile biology and age-related changes thereof, the prevalence of ED, its etiological factors in the older population, and contemporary treatment options geared toward the treatment of ED in aging and aged males.

\section{Prevalence and Etiology}

Notwithstanding variations in definitions and methodology, various large-scale studies substantiate the global presence of ED, and its close relationship to aging. The Massachusetts Male Aging Study for example, is a largescale longitudinal project investigating the effects of aging on male sexual health, among other domains. The authors reported a combined prevalence of minimal, moderate and complete impotence of no less than $52 \%$ [6]. The prevalence of complete impotence tripled from 5 to $15 \%$ between subject ages 40 and 70 years [6]. In the European Male Aging Study (EMAS), a collaborative effort of eight European centers investigating ED in a male population aged 40-79 with a mean age of 60 years old, $30 \%$ of the entire EMAS sample reported ED [7]. The prevalence of ED was higher in the older age groups, peaking in men 70 years and older (64\%). It was further shown that men in higher age groups, although more often affected, were less concerned with the presence of ED [7]. Approximately 617,000 new cases occur annually in men aged 40-69 in the US alone [8].

$\mathrm{ED}$ is strongly associated with advancing age. It logically follows that ED is therefore highly prevalent in the older population [9]. With the rapidly expanding aging population and the increase in life expectancy, an increase in the prevalence of ED is expected in the years to come. It is estimated that by $2025,9.5 \%$ of the worldwide population will be men older than 65 years of age [10]. By then, the number of men suffering from ED will reach 322 million worldwide. The relationship between age and ED is illustrated by the fact that the prevalence of ED rises steadily with age from $30.7 \%$ in men aged $57-64$ years, to $43.3 \%$ in men aged $75-85$ years [11]. In other studies, prevalence rates up to $77.5 \%$ are mentioned in patients aged 75 years and older [12]. However, not only the prevalence, but also the severity of ED increases with advancing age. The relationship between aging and ED is in part based on the increasing morbidities aged men experience, such as hy- pertension, vascular disease, chronic kidney disease, depression, and many others. Polypharmacy further contributes to the development of ED in the aging population. These concurrent conditions contribute to the development of ED via a multitude of pathways, aside from the changes induced by the process of aging itself.

\section{Physiology and Pathophysiology}

\section{Physiology}

For a good understanding of pathophysiological processes and treatment options for ED in aging men, we first briefly discuss the basic physiological processes involved in erectile biology. For a more elaborate discussion, we refer the reader to references [13] and [14]. Penile erection is a complex neurovascular phenomenon under hormonal control. Upon sexual arousal, pro-erectile impulses are generated in the parasympathetic erection centers of the limbic system and the hypothalamus. These impulses are mediated by predominantly dopaminergic neurons, whereas serotonin is the principle erection-inhibiting neurotransmitter. These central erectile mechanisms partially provide an explanation for diminished sexual function in aging-related central neurological conditions such as Parkinson's disease, in which dopaminergic neurotransmission is impaired. Dopamine-containing nerve endings impinge on oxy tocinergic cell bodies in the paraventricular nucleus which project, in turn, to extra-hypothalamic brain areas such as the hippocampus, the ventral medulla, and the spinal cord, which contains the sacral spinal erection centre in the S2-S4 region. In addition to central pathways, an erectogenic stimulus may originate in response to direct tactile stimulation of the penis, exciting afferent sensory neurons to the sacral spinal erection center.

Efferent neurons pass anterior and lateral to the rectum as the nervi erigentes to relay with nonadrenergic, noncholinergic fibers in the hypogastric plexus. These fibers run through the cavernous nerves which are located mainly dorsolateral to the prostate, and perforate the urogenital diaphragm to enter the cavernous bodies at the level of the crura. A central or reflexogenic neural stimulus leads to a release of nitric oxide (NO) from nerve terminals of the cavernous nerves in the corpus cavernosum. In addition, $\mathrm{NO}$ is released from the endothelium in response to release of acetylcholine and putatively also in response to the shear stress exerted at the walls of the penile sinusoids filling with blood. NO, which is gaseous in nature, diffuses into the cavernous smooth muscle cells 


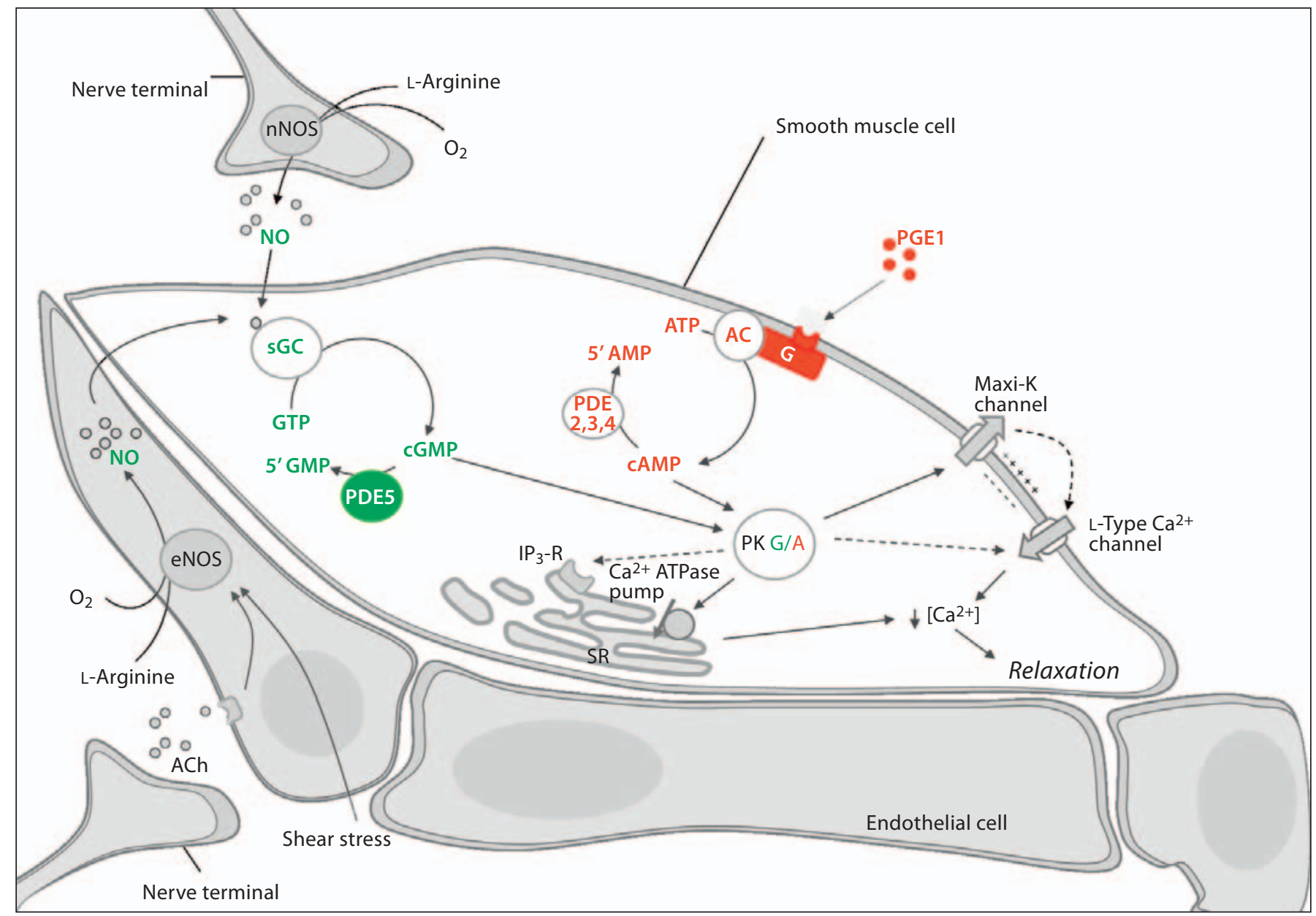

Fig. 1. Pathways leading to penile smooth muscle relaxation and erection. NO is released from nerve terminals in the corpus cavernosum in response to a neural stimulus and from the endothelium in response to the release of acetylcholine (ACh) and to the shear stress elicited by increased blood flow in the corporeal sinusoids. NO binds to soluble guanylate cyclase (sGC) and thereby activates this enzyme, which catalyses the breakdown of guanosine triphosphate (GTP) into cGMP. This pathway, the target of PDE5-inhibition, is depicted in green. Other pathways, which are initiated by PGE1, activate a G-protein $(\mathrm{G})$-coupled receptor, leading to activation of adenylil cyclase (AC), which catalyses the breakdown of adenosine triphosphate (ATP) into cyclic adenosine monophosphate (cAMP). This pathway, and thus target for intracavernosal injection of prostaglandin, is depicted in red. cGMP and cAMP activate protein kinase $\mathrm{G}$ and $\mathrm{A}$, respectively, which modulate potassium and calcium channels in the cell membrane, and the inositol triphosphate receptor $\left(\mathrm{IP}_{3}-\mathrm{R}\right)$ and the calciumATPase pump in the membrane of the sarcoplasmatic reticulum (SR). These events lead to a lowering of the cytosolic calcium concentration, which causes dissociation of calcium from calmodulin. Calmodulin in turn dissociates from myosin light chain kinase, thus inactivating it in turn leading to smooth muscle relaxation, and ultimately, to penile tumescence. Figure and legend adapted from Albersen et al. [14]. where it upregulates cyclic guanosine monophosphate (cGMP), which acts as a second messenger and initiates a chain of reactions ultimately resulting in a decrease in intracellular calcium and relaxation of the smooth muscle (fig. 1). Other mechanisms of smooth muscle relaxation are mediated by cGMP after binding of endogenous prostaglandins to their receptors (fig. 1). The relaxation of smooth muscle in the walls of the sinusoids and in the arterial walls allows rapid blood flow into the cavernosal sinusoids. The subsequent engorgement of the penis compresses the emissary veins, which drain the sinusoidal blood, against the tunica albuginea thereby halting venous outflow. A further increase in penile rigidity is established by contraction of the striated ischiocavernous muscles, increasing intracorporeal pressure to several hundreds $\mathrm{mm} \mathrm{Hg}$. 
The above described pro-erectogenic parasympathetic mechanisms are counterbalanced by sympathetic input from the cavernous nerves. The sympathetic nervous system is active when the penis is flaccid and carries out its anti-erectogenic effects by the release of norepinephrine from the nerve terminals, which stimulates the $\alpha_{1}$-adrenergic receptor on the cavernosal smooth muscle cells. This activates the phospholipase $\mathrm{C}$ pathway, enhancing influx of calcium and an increasing smooth muscle tone. The contraction induced by norepinephrine is potentiated by endothelin-1, which is released from the endothelial cells lining the sinusoidal spaces in response to adrenergic stimulation.

\section{Pathophysiology}

As stated above, ED in aging males is the result of various factors which exert negative effects on multiple levels in erectile biology. Herein, we focus on those processes typically involved in aging. However, many other disorders that are prevalent in aged males further contribute to the development of ED by interfering with erectile biology at multiple levels.

First, in the aging male the vascular supply to the penis is compromised. It has been shown in the rat that the internal pudendal artery is subject to an accelerated aging process compared to other vessels like the renal artery and the aorta. It was postulated that this effect was a consequence of the episodic significant increase in the hemodynamic load these small diameter vessels have to withstand. Morphological assessments showed medial thickening, and significantly reduced capacity for penile blood flow [15]. In humans, postmortem studies have revealed that aging is associated with increasing degrees of atherosclerotic vascular alteration in the arterial bed of the penis [16].

Second, aside from morphological changes, in multiple human arteries, $\alpha_{1}$-adrenergic receptor expression increases, and the relative proportion of $\alpha_{1}$-adrenergic receptor subtypes is modulated by aging. These changes are likely applicable to the human prostatic, bladder, and erectile tissue [17]. These changes translate functionally in a reduced efficacy of phenylephrine in inducing contractions of vascular smooth muscle strips in-vitro which was significantly greater for those isolated from the corpus cavernosum of older ( $>60$ years) men with ED than for those isolated from younger ( $<60$ years) men with ED. These results underline that aging also plays a role in adrenergic sensitivity in patients with ED [18]. Another factor contributing to impaired vasodilation in the corpus cavernosum and the penile arterial supply of the older man is endothelial dysfunction. It has been shown that the reduction in endothelial function occurs steadily with age in males, whereas in females the age-dependent reduction in endothelium-dependent vascular responsiveness becomes obvious only after the menopause [19]. Endothelial dysfunction is one of the main common denominators that link ED and cardiovascular disease, and the two disorders share various risk factors, of which age is the capital one. Furthermore, in the process of aging, the number of risk factors for endothelial dysfunction is augmented by an increase in comorbid conditions such as hypertension, dyslipidemia and diabetes. Endothelial dysfunction in aging has, among other factors, been attributed to the presence of NO scavengers in the corpus cavernosum, the most obvious candidates being superoxide anions, production of which is augmented in ageing endothelial cells [19]. This causative link is further strengthened by the fact that the decrease in endothelium-dependent vasodilatation with age in humans can be prevented by inhibitors of cyclooxygenase and vitamin C, both powerful antioxidants [19]. The presence of reactive oxygen species results in an inflammatory state of the endothelium resulting in predisposition to plaque formation and atherosclerosis, thereby further reducing blood flow to the erectile tissue. The changed state in the aged endothelium further results in the inactivation of eNOS through a decrease in phosphorylation of its positive regulatory site and an increase in phosphorylation of its negative regulatory site [20]. Not only the activity of eNOS is decreased, also the penile expression of eNOS is diminished in aged rats. The latter might be attributable to an increase in apoptosis of the endothelium which is not sufficiently replenished due to a lack of regeneration by endothelial progenitor cells [21]. Thus, a dysfunctional penile endothelium results in a decreased release of NO resulting in an increased vascular and sinusoidal smooth muscle tone.

Third, not only the endothelial supply of NO to the cavernosal smooth muscle is diminished. Penile nNOS activity and expression are diminished in aged animals, further reducing the availability of $\mathrm{NO}$ to the erectile tissue and thereby contributing to an increased sinusoidal and arterial smooth muscle tone. This is illustrated by a decreased intracavernosal pressure upon electrostimulation of the cavernous nerve in rodents. The findings of decreased nNOS and eNOS expression and activity are further supported by a decline in cGMP content in aged rat penises [22].

Fourth, both the penile extracellular matrix and the cavernous smooth muscle cells also are affected by aging. The percentage of smooth muscle steadily decreases with 
aging [23]. Furthermore, corpora cavernosa of aged men demonstrated excessive deposition of collagen fibers which resulted in corporal fibrosis. These changes are similar to those observed in the media of the penile arteries $[24,25]$. It has been postulated that these histologic changes in the aged corpora, like endothelial dysfunction, are caused by increased oxidative stress and/or other profibrotic factors that stimulate smooth muscle apoptosis and collagen deposition [16]. Changes in smooth muscle content and extracellular matrix proteins, particularly collagen and elastin, can provoke mechanical alterations of the penis, which reduce its elasticity and compliance. These alterations result in an impaired expandability of the corporeal tissue, and therefore the mechanism by which the expanding sinusoids compress the emissary veins against the tunica albuginea becomes defective. This results in corporeal venous leakage which typically presents as the inability to maintain an erection as is frequently seen in the aged male.

Finally, a factor contributing to the above-described changes in smooth muscle and collagen content of the corpus cavernosum is androgen deficiency. This condition is highly prevalent in aging males and has also been linked to loss of smooth muscle mass in the penis. Androgen deprivation in castrated animals results in a significant reduction in trabecular smooth muscle content and in a marked increase in connective tissue deposition [26]. These structural alterations are also associated with loss of erectile function. Ultrastructural studies demonstrated that cavernosal smooth muscle lining the sinusoids in castrated animals appeared disorganized, whereas in the intact animals the smooth muscle cells exhibited normal morphology [27]. In addition to the alterations in smooth muscle and connective tissue, fatcontaining cells have been observed in the subtunical region of penile tissue sections from orchiectomized animals [28, 29], potentially contributing to corporeal veno-occlusive dysfunction in aged men. Furthermore, the presence of androgens regulates the normal morphology and function of the cavernous nerves, and keeps the endothelium in a healthy condition. Thus, and rogen deficiency in aged males complicates erectile biology at multiple levels.

\section{Assessment of ED}

While ED used to be evaluated and treated in a disease-centered approach, like is common in many other fields in medicine, the current approach of ED is rather patient-centered. In this approach the physician consciously adopts the patient's perspective, and respects his and the partner's values and expectations $[13,30]$. ED in the aging male is more often than not of multifactorial origin and therefore in need of a holistic assessment. The initial evaluation of ED should include a complete medical, psychosocial and sexual history. As the evaluation of $\mathrm{ED}$ in the aging male is patient-centered, the goal should be not only to identify the specific erectile problem and potential underlying diseases, but more important, to get an idea of the patient expectations and reasons for consultation.

\section{Medical History}

The goal of history-taking should be to not only understand the specific erectile condition, but also to identify possible underlying and reversible or treatable disorders [30]. A thorough medical assessment is mandatory in the evaluation of erectile complaints in all patients, but is particularly important in the older male and in patients at intermediate and high risk for cardiovascular disease. These patients should undergo cardiovascular assessment before continuation of sexual activity and before initiating therapy for ED [31]. Patients are therefore subjected to a risk stratification which determines whether cardiovascular status permits sexual activity and pharmacological treatment of ED. Underlying conditions such as depression, diabetes, late-onset hypogonadism, metabolic syndrome, and medication/surgically induced causes of ED should be ruled out and if present, addressed accordingly. A thorough review of medications should identify the use of agents known to cause or exacerbate ED (such as antidepressants, antiandrogens, thiazides and beta-blockers). It is furthermore very important to assess for use of nitrate donors, which are absolute contraindications for therapy with PDE5 inhibitors, and some alpha-blockers which need a certain time interval between their use and the use of PDE inhibitors.

\section{Sexual History}

A thorough sexual history-taking can help in understanding the causes of ED. An adequate sexual history should include information about the current sexual relationship(s), both the emotional as well as the physical status of the patient and the partner, and the exact reasons for consulting unique to the patient or the couple [30]. Descriptive measures such as rigidity and duration of nocturnal erections, erections during masturbation and erections following sexual arousal should be discussed, as they can give clues about the etiology of ED. The onset of the 
problem and any situational factors that are linked to the occurrence of ED should be identified. It is necessary to determine whether ED is the primary sexual problem or if some other aspects of the sexual response cycle (desire, ejaculation, orgasm) are involved. Problems with arousal, ejaculation and difficulty reaching orgasm may be signs of underlying sexual dysfunctions such as late-onset hypogonadism, which is highly prevalent in this particular group of patients [9]. The impact of ED and other sexual dysfunctions on both general well-being and sexual satisfaction is an important issue, not only for the patient himself, but also for the partner. The intrapersonal impact of ED should not be underestimated, and therefore ideally is addressed in the presence of the partner. Open communication within the couple should be stimulated. As patients and their partners are likely bothered by discussing sexual issues, it is important that the clinician maintains an attitude of comfort and flexibility throughout the evaluation process [30].

The use of standardized questionnaires such as the International Index of Erectile Function can be useful instruments in assessing the severity of ED, in screening for other sexual dysfunctions, and in evaluating treatment outcome. However, questionnaires should not substitute for a detailed sexual history.

\section{Physical Examination}

Physical examination is an essential part of the assessment of ED, although it rarely identifies a specific cause. Like medical history taking, the physical exam is helpful in finding signs of underlying or comorbid conditions. It therefore should include a general screening examination, including cardiovascular, neurologic, and metabolic health status. Blood pressure and heart rate should be measured if they have not been assessed in the previous 3-6 months. Particular attention should be given to examination of the genitals and secondary sex characteristics. Deformities such as micropenis, chordee and Peyronie's disease may be identified by careful examination of the penis. Testing for genital and perineal sensation and the bulbocavernosus reflex is useful in assessing a possible neurogenic component. Assessment of testicular size is of importance as small testes and regression of secondary sex characteristics may indicate underlying hypogonadism [30].

\section{Laboratory Investigation}

Fasting glucose, lipids, and hormonal profiles are typically included in the laboratory investigation of the patient complaining from ED. In line with history taking and physical examination, these tests are performed to iden- tify specific causes like hypogonadism, or to assess the role of medical comorbidities such as diabetes and hyperlipidemia. The laboratory investigation may identify treatable conditions or previously undetected medical illnesses that may contribute directly to ED. Additional laboratory tests may be performed at the discretion of the physician based on the medical history and/or physical exam.

\section{Technical Investigation}

Generally when treating any patient with any disorder, a specific diagnosis is needed to formulate a treatment plan. In most cases of ED, treatment can be initiated without extensive technical investigation. Excluding some minimally invasive technical investigations such as color duplex ultrasound, the value of additional technical investigations in the older patient is limited, as the implications of the results do not change therapy significantly in this specific population. Investigations such as dynamic infusion cavernosometry, cavernosography, arteriography and neurophysiologic testing are reserved for assessment of younger patients in whom vascular or neurologic reconstructive surgery might be indicated. Cases that might need further specialist investigations include patients suffering from Peyronie's disease, complex neuropsychiatric problems, severe relationship issues, complicated endocrinological disorders, failure of initial treatment or previous pelvic trauma.

\section{Treatment}

\section{Nonpharmacological Treatment \\ Counseling}

Before the initiation of treatment, it is important to set realistic outcome goals in open communication with the patient and his partner. Reviewing the findings of the initial evaluation with the patient or the couple can be used as a starting point to educate about the anatomy and physiology of sexual function and to provide appropriate understanding of the patient-specific pathophysiology of ED. Current oral pharmacological treatments for ED do not 'cure' ED but can generally be relied upon to improve erectile function in patients without important comorbidities or underlying disorders such as diabetes, or after radical prostatectomy. It should be clarified to the older patient that due to comorbidities and multiple pathophysiologic changes in the penis, vasculature and nervous system, a fully rigid erection will be hard to accomplish with the use of oral pharmacotherapy. The patient and his partner should further be educated about possible 
Table 1. Pharmacological and mechanical treatment options for ED

\begin{tabular}{|c|c|c|c|c|}
\hline Product & Dose & $\begin{array}{l}\text { Dosing } \\
\text { frequency }\end{array}$ & Advantages & Side effects \\
\hline $\begin{array}{l}\text { Sildenafil } \\
\text { Vardenafil } \\
\text { Tadalafil }\end{array}$ & $\begin{array}{l}25,50,100 \mathrm{mg} \\
2.5,5,10,20 \mathrm{mg} \\
2.5,5,10,20 \mathrm{mg}\end{array}$ & $\begin{array}{l}\text { on demand } \\
\text { or daily }\end{array}$ & $\begin{array}{l}\text { most effective oral pharmacotherapy; } \\
\text { safe; available on demand as well as } \\
\text { continuous low dose } \\
\text { (vardenafil } 2.5 \mathrm{mg} \text {, tadalafil } 2.5 \mathrm{mg} \text { ) }\end{array}$ & $\begin{array}{l}\text { cost, headache, facial flushing, } \\
\text { nasal congestion, myalgia, back pain, } \\
\text { and blurred or disturbed vision }\end{array}$ \\
\hline Yohimbine & $5-15 \mathrm{mg}$ & $\begin{array}{l}\text { three times } \\
\text { daily }\end{array}$ & natural product & $\begin{array}{l}\text { limited evidence; anxiety, } \\
\text { hypertension, tachycardia }\end{array}$ \\
\hline Apomorphine SL & $4 \mathrm{mg}$ & on demand & $\begin{array}{l}\text { rapidly absorbed, available for } \\
\text { patients taking nitrates }\end{array}$ & $\begin{array}{l}\text { lower efficacy than PDE5-I; } \\
\text { nausea, headache and dizziness }\end{array}$ \\
\hline $\begin{array}{l}\text { PGE1 } \\
\text { Phentolamine } \\
\text { Papaverine } \\
\text { VIP }\end{array}$ & $\begin{array}{l}5-40 \mu \mathrm{g}^{1} \\
1.25-2 \mathrm{mg}^{1} \\
30-110 \mathrm{mg}^{1} \\
25 \mu \mathrm{g}^{1}\end{array}$ & on demand & $\begin{array}{l}\text { direct action, broad efficacy, safety; } \\
\text { effective in neurogenic ED }\end{array}$ & $\begin{array}{l}\text { priapism, painful erections, penile } \\
\text { fibrosis; injection training needed }\end{array}$ \\
\hline MUSE & $\begin{array}{l}125,250,500 \\
1,000 \mu \mathrm{g}\end{array}$ & on demand & no injection needed & $\begin{array}{l}\text { hypotension, syncope, urethral } \\
\text { burning or pain in the patient, } \\
\text { vaginal irritation in partner }\end{array}$ \\
\hline $\begin{array}{l}\text { Vacuum } \\
\text { constriction } \\
\text { device }\end{array}$ & & on demand & minimally invasive, not expensive & $\begin{array}{l}\text { unnatural erection; absence of } \\
\text { spontaneity; bruising, pain; cold } \\
\text { penis; pivoting at constriction band }\end{array}$ \\
\hline Penile prosthesis & & permanent & high success and satisfaction rates & complications, irreversible \\
\hline
\end{tabular}

pharmacological and nonpharmacological treatment options (table 1). The choice of treatment should be made by the patient and partner supported by the physician, who ideally does not assume an authoritative role in this decision process [30]. Alternative forms of intimacy that do not rely on penetrative sexual intercourse and satisfaction associated with these activities are further discussed. Satisfaction with sex life is directly related to metal health; this implies that if men with ED can learn to be satisfied with other forms of intimacy, mental health could be preserved [32]. Referral to a sexologist or relationship therapist for more extensive counseling might be indicated if intrapersonal problems are encountered. Furthermore, in some patients with psychogenic or mixed psychogenicorganic ED, specialized psychosexual therapy may help relieve anxiety and remove unrealistic expectations associated with medical or surgical therapy.

\section{Lifestyle Changes}

Obesity, sedentary lifestyle and cigarette smoking are the most common lifestyle factors that cause or contribute to ED. Therefore, patients should be educated about the beneficial effects of weight loss, increasing exercise, and quitting smoking on erectile function. Furthermore, the addition of a statin to the therapy of men suffering from ED and hypercholesterolemia has shown beneficial effects on erectile function [33].

\section{Medication Changes}

Multiple medications can cause, or contribute to preexisting ED. Diuretics, particularly thiazides, but also antihypertensives including $\beta$-adrenergic antagonists and nonspecific $\alpha$-antagonists have frequently been described to cause or worsen ED. Furthermore, tricyclic antidepressants have been linked to both loss of libido up to $70 \%$ and ED in $1.7-6.4 \%[34,35]$. These drugs are known to increase ejaculatory latency time and are currently even prescribed for the treatment of premature ejaculation. Androgen blockade in the case of prostate cancer treatments has similar effects on erectile function and libido. Aside from these specific drugs, a variety of compounds such as antihistamines, nonsteroidal anti-inflammatory drugs, anti-arrythmics and drugs for the treatment of Parkinson's disease have been linked to ED on a more anecdotal 
basis. In most situations, changing to a different class of drug, if possible, is a feasible first step [30]. Regarding antihypertensives, newer agents such as calcium-channel blockers and angiotensin-converting enzyme inhibitors may reverse ED in some patients, and switching to an $\alpha_{1-}$ specific agonist, such as doxazosin, preserves erectile function. Angiotensin receptor blockers, such as valsartan, losartan and candesartan may further have beneficial effects on erectile function. Regarding antidepressants, substitution, drug holidays and dosage reduction have been proposed [35]. This should be done in agreement with the physician prescribing the specific medication. Aside from medications, recreational and frequently abused drugs such as alcohol, cocaine, marijuana, amphetamines and opiates have been linked to ED, and the patient should be counseled about these facts [30]. As stepby step review of the patient medications should be performed when treating $\mathrm{ED}$, to investigate whether nonessential drugs with negative impact on erectile function can be abandoned, and whether essential drugs can be replaced by their counterparts or drugs from another family with less impact on erectile function.

\section{Pharmacotherapy}

Selective PDE5I

PDE5I are intracellular signal amplifiers. They are nonhydrolysable analogs of cGMP and exert their beneficial effects on smooth muscle relaxation by competitively binding to the catalytic site of PDE5, the enzyme responsible for breakdown of cGMP to 5 '-guanosine monophosphate (GMP). By slowing the degradation of cGMP by PDE5, these drugs produce an intracellular accumulation of cGMP in smooth muscle cells in the corpus cavernosum and in the walls of the supplying arteries [14]. Currently, vardenafil, sildenafil and tadalafil are marketed worldwide, while newer compounds such as udenafil and mirodenafil are approved in few countries while they are still in phase-3 trials elsewhere [14].

As the endogenous production of NO is decreased in aging (vide supra), and further diminished by comorbidities such as hypogonadism, diabetes and atherosclerosis, it logically follows that PDE5I have lower response rates in older than in younger patients [14]. Nevertheless, they are recommended as the first-line pharmacotherapeutic option due to their ease of use, and excellent safety profile, also in elderly [36]. While some men report that PDE5I are not efficacious with first dose, results generally improve with repeated dosing. Patient education should cover this topic, address proper dosing intervals, and stress the fact that sexual stimulation is necessary for the drug to be effective [9]. Overall efficacy rates are 60$70 \%$ with on-demand treatment regimens [5]. Of the patients that initially do not respond to PDE5I, between 30$50 \%$ may be converted to responders by counseling the patient and his partner. Current recommendations advise starting treatment with a dose of $50 \mathrm{mg}$ for sildenafil and $10 \mathrm{mg}$ for vardenafil and tadalafil. Some patients who do not benefit from PDE5I therapy on demand, may benefit from a daily low-dose administration [37,38]. For this indication, tadalafil is available for daily use in the 2.5 and $5 \mathrm{mg}$ dosage, and vardenafil was marketed in a 2.5 mg daily dosage in some countries. Sildenafil has been used in clinical experimental setting in a daily dose of 25 $\mathrm{mg}$ [39]. In the aging male suffering from ED and lateonset hypogonadism, addition of testosterone supplements might enhance the efficacy of PDE5I therapy. This is based on the finding that physiological testosterone levels keep the erectile tissue and the supplying nerves in a healthy condition. Furthermore, testosterone increases the bioavailable NO in the cavernous smooth muscle and thus increases efficacy of PDE5 inhibition [40].

The choice of PDE5I is basically up to the patient and partner, guided by the advice of the physician. Among the currently marketed agents, the most clinically significant differences are found in duration of action. The reported half-life of sildenafil and vardenafil are 4-6 h, while tadalafil has a longer bioactivity with a half-live time of $17-21 \mathrm{~h}$. The duration of activity that is seen with sildenafil and vardenafil appears to be suited to the average couples' patterns of sexual interaction. Tadalafil has brought a shift in paradigm in treating ED and potentially enhances sexual spontaneity by the longer half-life time.

The safety profile of the currently available PDE5I is excellent, based on post-marketing data and further demonstrated by the recent FDA approvals for daily use of PDE5I, as mentioned above [14]. In postmarketing pharmacological surveillance, no increase in myocardial infarction rates in patients who received these agents has occurred compared to expected rates in age-matched populations [14]. There are certain heart-related precautions in the use of PDE5I which are important to note regarding the high prevalence of cardiac comorbidity in the aging male. PDE5I are relatively contraindicated in patients with unstable angina pectoris, recent myocardial infarction, certain arrhythmias, and poorly controlled hypertension. Patients who are treated with nitrates or nitrate donors should not take PDE5I, and usage of PDE5I with alpha-blockers may result in postural hypotension. The most common adverse events from PDE5I are attributable to specific inhibition of PDE5 and vaso- 
dilatation in tissues other than the penis, and include headache, facial and ocular hyperemia, nasal congestion, myalgia, and back pain. Visual blurring is a relatively frequently occurring side effect which is attributed to crossreactivity with PDE6 in the retina. In a study assessing the safety of sildenafil in men aged 60-78, the most commonly experienced adverse events were flushing and dyspepsia, which occurred in 6.8 and $2.3 \%$, respectively. No patients discontinued sildenafil treatment due to adverse events [36]. In a retrospective study comparing the safety of vardenafil in patients aged 65 years or older with their younger counterparts, the most common treatmentemergent adverse events were headache, rhinitis, flushing and dyspepsia, which were mild to moderate, transient and unrelated to age [41]. Also for tadalafil, subgroup analysis in a large efficacy and safety study revealed no differences between the incidences of adverse events in tadalafil-treated men 65 years or older compared with younger men [42]. In general, adverse events account for only a quarter of cases in which PDE5I are discontinued, while the most common reason for discontinuation of PDE5I is a lack of efficacy [43].

\section{Other Oral Pharmacotherapy}

Apomorphine SL (Sublingual). Apomorphine is a centrally acting nonselective dopamine agonist which enhances naturally occurring pro-erectile signals. It is administered sublingually and rapidly absorbed into the systemic circulation. Therefore erections are achieved in approximately $20 \mathrm{~min}$ in the majority of the patients. It is available in two dosages, 2 and $3 \mathrm{mg}$. The most common adverse events include nausea, headache and dizziness and are due to nonspecific binding to various subtypes of the dopamine receptor. The relatively high frequency of adverse events has limited the clinical usefulness of the drug. Apomorphine is not contraindicated in patients taking nitrates, and therefore represents first-line oral treatment in this class of patients, although efficacy and tolerability are generally much lower than PDE5I [44]. It is most effective in mild-moderate ED. As the severity of ED generally increases with advancing age, the clinical applicability of this dopamine agonist may be limited in aging patients. However, since it has a different mode of action compared to PDE5I, there may be a role for combination therapy in patients who respond suboptimally to PDE5I and do not want to take the step to intracavernous or intraurethral therapy.

Herbal Supplements. Herbal and nutritional supplements generally lack strong evidence in the field of ED and should not be seen as a recommended mainstream medical therapy. Yohimbine is a peripherally and centrally acting alpha-blocking alkanoid. It is derived from the bark of an evergreen tree along with some other psychoactive alkanoids. There is little evidence on its efficacy, and it is therefore not generally recommended for management of ED. Ginseng is another widely known aphrodisiac which has been suggested to increase erectile function. Data on this substance are preliminary and need further trials. A third herbal substance may hold promise for the future therapy of $\mathrm{ED}$; icariin is a flavonol glycoside and major constituent of horny goat weed. In China, horny goat weed, or Herba epimedii has been used for centuries to enhance sexual drive and performance. Recently, it was discovered that this enhancement is due to an inhibitory effect of both PDE 4 and PDE5 by icariin [45]. Icariin was able to prevent fibrotic alterations in the corpus cavernosum after denervation in rats when administered daily by oral gavage [46]. Nutritional supplements such as antioxidants may reduce erectile tissue damage by radical oxygen species [47]. They have been suggested to enhance the efficacy of PDE5I, but this finding needs to be validated in large-scale trials [30].

\section{Vacuum Constriction Devices}

The vacuum constriction device is a manually operated device that creates negative pressure around the penis, resulting in passive engorgement of the sinusoidal spaces and the subcutaneous tissues. Its use is advised in patients who do not wish medical therapy for ED or in those who do not respond adequately to medical therapy and do not wish to undergo penile implantation surgery. Maintenance of erection is facilitated by application of a rubber cuff applied around the penile base. Although effective in up to $90 \%$ of patients, the use of a vacuum device might be perceived as disturbing. Patients should be counseled that erections achieved with a VCD do not appear natural but rather cool, cyanotic, and that instability may occur as the turgidity occurs only distal to the constriction band [48]. Local side effects are relatively minor and include bruising, some discomfort and ejaculatory obstruction. It is advised to limit the use of the constriction band to $30 \mathrm{~min}$ to avoid skin necrosis. Relative contraindications to VCD use include bleeding disorders and the use of anticoagulants [44].

Intracavernous and Intraurethral Administration of Vasoactive Substances

Before the advent of PDE5I in the late 1990s, intracavernous and intraurethral administration of vasoactive substances were the only nonsurgical treatment options 
for ED. It is the recommended second line treatment in patients that fail to respond PDE5I therapy. This treatment provides an alternative with broad efficacy, good safety profile, and a rapid onset of action. The most commonly utilized substances include prostaglandin E1 (PGE1), phentolamine, and papaverine. PGE1 and papaverine cause cavernous smooth muscle relaxation by elevation of the intracellular concentration of the second messengers cGMP and cyclic adenosine monophosphate. Phentolamine is an $\alpha$-adrenergic antagonist. These mechanisms of action are independent of the endogenous supply of NO, and the substances are therefore suitable for older men who do not respond to PDE5I therapy. Overall satisfaction rates with intracavernous therapy are almost $80 \%$. PGE1 is also available as an intraurethral administrated pellet (medicated urethral system/suppository for erection; MUSE ${ }^{\circledR}$ ). Urethral and intracavernosal administration of vasoactive substances results in erection within several minutes which last half an hour to $2 \mathrm{~h}$, depending on the used dosage [30,44].

Adverse events from these therapies include priapism, variable degrees of pain with injection in about half of patients, and penile fibrosis after long-term use. MUSE has been associated with hypotension, syncope, urethral burning or pain, and vaginal irritation in the partner. Relative contraindications to injection therapy include men who have a history of priapism and those with bleeding disorders. If an erection lasts longer than $4 \mathrm{~h}$, the patient is advised to seek advice of the treating physician [44].

\section{Surgical Treatment of ED}

Surgical treatment is indicated in patients who have the desire to achieve erections and in whom conservative pharmacotherapy has failed, or those declining pharmacotherapy. While revascularization, venous ligation and reconstructive procedures have been described, these are reserved for the treatment of ED in young patients with specific indications [30]. More commonly, a penile prosthesis is implanted.

There are three types of penile prosthesis; 2- or 3-piece inflatable devices, semirigid devices, and soft silicone devices. The latter technique is being abandoned as it was a supportive prosthesis and patients with partial ED now respond to pharmacotherapy. The three-piece inflatable prosthesis is currently the preferred device and consists of two inflatable rods, connected to a pump device which is placed in the scrotum and a reservoir which is placed in the preperitoneal space in the lower abdomen. The semirigid device is indicated in patients with limited manual dexterity and can be used when the patient is unable to undergo spinal or general anesthesia, as the corpora cavernosa and the skin incision can be anesthetized locally. Both patient and partner satisfaction is very high and satisfaction rates reach $90-98 \%$ for the three-piece inflatable devices [48]. Careful counseling before placement of a penile prosthesis is of capital importance and limits postoperative dissatisfaction issues.

Penile prosthesis placement is complicated by infection of the prosthesis in approximately $1-2 \%$ of the patients, but these percentages are decreasing due to novel coating techniques which allow the surgeon to immerse the device in an antibiotic solution of their choice. Another complication is prosthesis erosion, although this is quite rare in three-piece devices [48]. Bothersome effects of penile prosthesis placement are auto-inflation, which can occur during increases of the intra-abdominal pressure, and downward drooping of the glans due to lack of glandular engorgement during erection. Some patients also complain of erectile length loss with prosthesis placement, especially in patients with Peyronie's disease and after radical prostatectomy. The latter has been successfully treated with concomitant PDE5I therapy or MUSE pellet insertion [48]. Currently implanted prostheses have reported survival times of approximately $60 \%$ after 15 years [48].

If Peyronie's disease is diagnosed, it can be surgically treated, keeping in mind that surgery should be delayed until the disease has stabilized and curvature has not progressed for 6 months or longer [30]. The Nesbit procedure used to be standard treatment, and consist of shortening the penis on the side opposite to the curvature to cancel out the amount of the curve. The Horton-Devine procedure consists of resection of the plaque and replacement by a graft which can be of various origins (fascia lata, buccal mucosa, porcine small intestinal submucosa xenograft, etc). The third option, which is indicated in patients with Peyronie's disease combined with severe ED, is the placement of a penile prosthesis, either or not in combination with other reconstructive surgeries.

\section{Future Directions in the Treatment of ED in the Aging Male}

As mentioned above, the ED market is rapidly expanding due to advancing age of the general population. This prospect has led to a surge in ED research which translates in an increasing body of literature advocating new therapeutic options for the condition. Pharmaceutical 
companies are highly interested in this expanding market which results in the development and investigation of various novel compounds. By influencing targets in different pathways leading to the development of penile erection, a variety compounds that are currently in development, such as guanylil cyclase activators, Rho-kinase inhibitors and maxi-K channel openers will undoubtedly cause major shifts in treatment strategies of ED. Currently available ED guidelines recommend treatment algorithms that are virtually identical for every patient, regardless of the age of the patient and the underlying pathology causing ED [14]. However, currently available oral pharmacotherapy has limited efficacy in older patients due to the lack of endogenous NO supply. Some of these newer compounds bypass the NO pathway, and are therefore expected to have good efficacy in difficult to treat older patients suffering from ED [14].

\section{Conclusion}

Although there generally exists a decline in the frequency of sexual activity with advancing age, the desire to remain sexually active persists in many men. Increasing comorbidities and pathological changes in the erec- tile tissue and supplying vasculature however, result in a high prevalence of ED in this population. When assessing $\mathrm{ED}$ in the older patient, it is of utmost importance to recognize and treat underlying systemic disorders when addressing the ED. Counseling should be carried out to established realistic treatment outcomes. Various pharmacological, nonpharmacological and surgical options are safe and efficacious in the older patient population. Future research will improve our ability to provide for the sexual health needs of older men.

\section{Acknowledgements}

M.A. is a fellow of Research Foundation - Flanders, a scholar of the European Society of Surgical Oncology, the Federico Foundation and Belgische Vereniging voor Urologie, and received an unrestricted research grant from Bayer Healthcare Belgium.

\section{Disclosure Statement}

M.A. received an unrestricted research grant from Bayer Healthcare Belgium. T.F.L. is a consultant of Pfizer, Lilly, Bayer, Medtronic and Auxillium, and is a board member of Genix. He has received a research grant from American Medical Systems.

\section{References}

1 Lindau ST, Schumm LP, Laumann EO, Levinson W, O'Muircheartaigh CA, Waite LJ: A study of sexuality and health among older adults in the United States. N Engl J Med 2007;357:762-774.

-2 Smith LJ, Mulhall JP, Deveci S, Monaghan N, Reid MC: Sex after seventy: a pilot study of sexual function in older persons. J Sex Med 2007;4:1247-1253.

$3 \mathrm{NIH}$ Consensus Conference: Impotence. NIH Consensus Development Panel on Impotence. JAMA 1993;270:83-90.

4 Uckert S, Mayer ME, Stief CG, Jonas U: The future of the oral pharmacotherapy of male erectile dysfunction: things to come. Expert Opin Emerg Drugs 2007;12:219-228.

5 Hatzimouratidis K, Hatzichristou DG: A comparative review of the options for treatment of erectile dysfunction: which treatment for which patient? Drugs 2005;65:16211650 .

-6 Feldman HA, Goldstein I, Hatzichristou DG, Krane RJ, McKinlay JB: Impotence and its medical and psychosocial correlates: results of the Massachusetts male aging study. J Urol 1994;151:54-61.
7 Corona G, Lee DM, Forti G, O’Connor DB,
Maggi M, O’Neill TW, et al: Age-related changes in general and sexual health in middle-aged and older men: results from the European Male Ageing Study (EMAS). J Sex Med 2010;7:1362-1380.

$>8$ Russell ST, Khandheria BK, Nehra A: Erectile dysfunction and cardiovascular disease. Mayo Clin Proc 2004;79:782-794.

$\checkmark$ Albersen M, Shindel AW, Lue TF: Sexual dysfunction in the older man. Rev Clin Gerontol 2009;19:237-248.

$\checkmark 10$ Ayta IA, McKinlay JB, Krane RJ: The likely worldwide increase in erectile dysfunction between 1995 and 2025 and some possible policy consequences. BJU Int 1999;84:5056

11 Laumann EO, Waite LJ: Sexual dysfunction among older adults: prevalence and risk factors from a nationally representative US probability sample of men and women 57-85 years of age. J Sex Med 2008;5:2300-2311.

12 Saigal CS, Wessells H, Pace J, Schonlau M, Wilt TJ: Urologic Diseases in America Project. Predictors and prevalence of erectile dysfunction in a racially diverse population. Arch Intern Med 2006;166:207-212.
13 Lue TF: Erectile dysfunction. N Engl J Med 2000;342:1802-1813.

14 Albersen M, Shindel AW, Mwamukonda KB, Lue TF: The future is today: emerging drugs for the treatment of erectile dysfunction. Expert Opin Emerg Drugs 2010;15:467-480.

15 Hannan JL, Blaser MC, Oldfield L, Pang JJ, Adams SM, Pang SC, et al: Morphological and functional evidence for the contribution of the pudendal artery in aging-induced erectile dysfunction. J Sex Med 2010;7:33733384

16 El-Sakka AI, Yassin AA: Amelioration of penile fibrosis: myth or reality. J Androl 2010; 31:324-335.

17 Rudner XL, Berkowitz DE, Booth JV, Funk BL, Cozart KL, D’Amico EB, El-Moalem H, Page SO, Richardson CD, Winters B, Marucci L, Schwinn DA: Subtype specific regulation of human vascular alpha(1)-adrenergic receptors by vessel bed and age. Circulation 1999; 100:2336-2343. 
18 Christ GJ, Stone B, Melman A: Age-dependent alterations in the efficacy of phenylephrine-induced contractions in vascular smooth muscle isolated from the corpus cavernosum of impotent men. Can J Physiol Pharmacol 1991;69:909-913.

19 Vanhoutte PM: Ageing and endothelial dysfunction. Eur Heart J Suppl 2002;4(suppl A):A8-A17.

20 Musicki B, Kramer MF, Becker RE, Burnett AL: Age-related changes in phosphorylation of endothelial nitric oxide synthase in the rat penis. J Sex Med 2005;2:347-355.

-21 Aversa A, Bruzziches R, Francomano D, Natali M, Gareri P, Spera G: Endothelial dysfunction and erectile dysfunction in the aging man. Int J Urol 2010;17:38-47.

22 Park CS, Ryu SD, Hwang SY: Elevation of intracavernous pressure and NO-cGMP activity by a new herbal formula in penile tissues of aged and diabetic rats. J Ethnopharmacol 2004;94:85-92.

23 Wespes E: The ageing penis. World J Urol 2002;20:36-39.

24 Ferrini MG, Davila HH, Valente EG, Gonzalez-Cadavid NF, Rajfer J: Aging-related induction of inducible nitric oxide synthase is vasculo-protective to the arterial media. Cardiovasc Res 2004;61:796-805.

- 25 Ferrini M, Magee TR, Vernet D, Rajfer J, Gonzalez-Cadavid NF: Aging-related expression of inducible nitric oxide synthase and markers of tissue damage in the rat penis. Biol Reprod 2001;64:974-982.

-26 Traish AM, Munarriz R, O'Connell L, Choi S, Kim SW, Kim NN, et al: Effects of medical or surgical castration on erectile function in an animal model. J Androl 2003;24:381-387.

- 27 Rogers RS, Graziottin TM, Lin CS, Kan YW, Lue TF: Intracavernosal vascular endothelial growth factor (VEGF) injection and adenoassociated virus-mediated VEGF gene therapy prevent and reverse venogenic erectile dysfunction in rats. Int J Impot Res 2003;15: 26-37.

28 Traish A, Kim N: The physiological role of androgens in penile erection: regulation of corpus cavernosum structure and function. J Sex Med 2005;2:759-770.
29 Traish AM, Kim N: Weapons of penile smooth muscle destruction: androgen deficiency promotes accumulation of adipocytes in the corpus cavernosum. Aging Male 2005; 8:141-146.

30 Lue TF, Broderick GA: Evaluation and nonsurgical management of erectile dysfunction and premature ejaculation; in CampbellWalsh Urology ed 9. Amsterdam, Elsevier, 2007.

31 Jackson G, Rosen RC, Kloner RA, Kostis JB: The second Princeton consensus on sexual dysfunction and cardiac risk: new guidelines for sexual medicine. J Sex Med 2006;3:28-36.

-32 Korfage IJ, Pluijm S, Roobol M, Dohle GR, Schroder FH, Essink-Bot ML: Erectile dysfunction and mental health in a general population of older men. J Sex Med 2009;6:505512.

33 Saltzman EA, Guay AT, Jacobson J: Improvement in erectile function in men with organic erectile dysfunction by correction of elevated cholesterol levels: a clinical observation. J Urol 2004;172:255-258.

34 Montejo-Gonzalez AL, Llorca G, Izquierdo JA, Ledesma A, Bousono M, Calcedo A, et al: SSRI-induced sexual dysfunction: fluoxetine, paroxetine, sertraline, and fluvoxamine in a prospective, multicenter, and descriptive clinical study of 344 patients. J Sex Marital Ther 1997;23:176-194.

35 Rosen RC, Lane RM, Menza M: Effects of SSRIs on sexual function: a critical review. J Clin Psychopharmacol 1999;19:67-85.

36 Fujisawa M, Sawada K: Clinical efficacy and safety of sildenafil in elderly patients with erectile dysfunction. Arch Androl 2004;50: 255-260.

37 Bella AJ, Deyoung LX, Al-Numi M, Brock GB: Daily administration of phosphodiesterase type 5 inhibitors for urological and nonurological indications. Eur Urol 2007;52: 990-1005.

38 Shindel AW: Update on phosphodiesterase type 5 inhibitor therapy part 1: recent studies on routine dosing for penile rehabilitation, lower urinary tract symptoms, and other indications (CME). J Sex Med 2009;6:17941808 .
39 Konstantinopoulos A, Giannitsas K, Athanasopoulos A, Spathas D, Perimenis P: The impact of daily sildenafil on levels of soluble molecular markers of endothelial function in plasma in patients with erectile dysfunction. Expert Opin Pharmacother 2009;10: 155-160.

-40 Shabsigh R, Kaufman JM, Steidle C, PadmaNathan H: Randomized study of testosterone gel as adjunctive therapy to sildenafil in hypogonadal men with erectile dysfunction who do not respond to sildenafil alone. J Urol 2004;172:658-663.

41 Giuliano F, Donatucci C, Montorsi F, Auerbach S, Karlin G, Norenberg C, et al: Vardenafil is effective and well-tolerated for treating erectile dysfunction in a broad population of men, irrespective of age. BJU Int 2005; 95:110-116.

42 Brock GB, McMahon CG, Chen KK, Costigan T, Shen W, Watkins V, et al: Efficacy and safety of tadalafil for the treatment of erectile dysfunction: results of integrated analyses. J Urol 2002;168:1332-1336.

43 Hatzimouratidis K, Hatzichristou D: Phosphodiesterase type 5 inhibitors: the day after. Eur Urol 2007;51:75-88.

44 Hatzimouratidis K, Amar E, Eardley I, Giuliano F, Hatzichristou D, Montorsi F, et al: Guidelines on male sexual dysfunction: erectile dysfunction and premature ejaculation. Eur Urol 2010;57:804-814.

45 Ning H, Xin ZC, Lin G, Banie L, Lue TF, Lin CS: Effects of icariin on phosphodiesterase-5 activity in vitro and cyclic guanosine monophosphate level in cavernous smooth muscle cells. Urology 2006;68:1350-1354.

46 Shindel AW, Xin ZC, Lin G, Fandel TM, Huang YC, Banie L, et al: Erectogenic and neurotrophic effects of icariin, a purified extract of horny goat weed (Epimedium spp.) in vitro and in vivo. J Sex Med 2010;7:15181528

47 Jones RW, Rees RW, Minhas S, Ralph D, Persad RA, Jeremy JY: Oxygen free radicals and the penis. Expert Opin Pharmacother 2002;3:889-897.

-48 Hellstrom WJ, Montague DK, Moncada I, Carson C, Minhas S, Faria G, et al: Implants, mechanical devices, and vascular surgery for erectile dysfunction. J Sex Med 2010;7:501523. 